\title{
The Baboon Spider Atlas - using citizen science and the 'fear factor' to map baboon spider (Araneae: Theraphosidae) distributions and diversity in Southern Africa
}

\author{
Heather Campbell \& lan Engelbrecht \\ Department of Zoology and Entomology, University of Pretoria, Pretoria, 0002, South Africa. \\ Corresponding author email: heather campbell@hotmail.co.uk
}

\begin{abstract}
1. Charismatic invertebrates are popular subjects for citizen science but it is harder to engage the public in research on animals that are perceived as dangerous. Many successful citizen science projects exist in North America and Europe, but with the increased use of new technologies and social media there is a greater capacity to expand citizen science to less developed regions.
\end{abstract}

2. Baboon spiders are African members of the tarantula family. They are threatened by habitat loss and illegal harvesting for the pet trade, but conservation efforts are hampered by a lack of knowledge on their ecology.

3. Here we describe the Baboon Spider Atlas, a project combining traditional research with citizen science to map the diversity and distributions of baboon spiders (Araneae:

Theraphosidae) in Southern Africa. Our project embraces the 'fear factor' associated with spiders to obtain photographic records from the public.

4. The Baboon Spider Atlas has assembled the largest database of information on baboon spiders in Southern Africa and is providing novel insights into their biology. Distribution ranges have been extended and potential new species discovered. Preliminary results suggest that their distribution may be limited more by cold, wet climatic conditions than hot, dry conditions. Records for wandering adult females and immatures highlight a previously undocumented behaviour and challenges the notion that baboon spiders are sedentary 
animals. Ultimately the project is generating the data needed for effective conservation and motivating further research that will provide a better understanding of baboon spider biology.

Keywords: Citizen science, spiders, Africa, biodiversity, mapping, species distributions, monitoring, conservation, databases

\section{Introduction}

Global threats to biodiversity from anthropogenic activities include unsustainable resource use, climate change, pollution, habitat loss, and introduction of invasive species. To monitor and assess the impacts of global change and consequently implement effective conservation strategies requires baseline data on species diversity and their geographic distributions (Joppa et al., 2016; Powney \& Isaac, 2015; Robertson et al., 2010). Tropical countries are often megadiverse but with developing economies are not able to invest substantially in biodiversity and conservation research (Fazey et al., 2005). Citizen science is a potential tool that can be used to fill this investment gap. South Africa has a successful history of projects with a significant citizen science component resulting in the production of atlases and red list assessments (Bates et al., 2014; Mecenero et al., 2013). One such project, the South African National Survey of Arachnida (Dippenaar-Schoeman et al., 2015), is a comprehensive distribution dataset for all arachnid taxa in South Africa.

Baboon spiders are a group of African tarantulas, belonging to the family Theraphosidae (Raven, 1985), but used here to specifically refer to the only subfamily recorded from southern Africa, the Harpactirinae (Tarantupedia, 2017). Baboon spiders are the largest bodied spiders in southern Africa, ranging from 10 to $50 \mathrm{~mm}$. Most species live in the ground and occupy a single burrow for their entire lifetime. Females reproduce once a year, producing between 10 and 100 
offspring that take several years to reach maturity. They are thought to be sedentary and remain in or near their burrows to hunt, the exception being adult males that will wander in search of mates (Dippenaar-Schoeman, 2002).
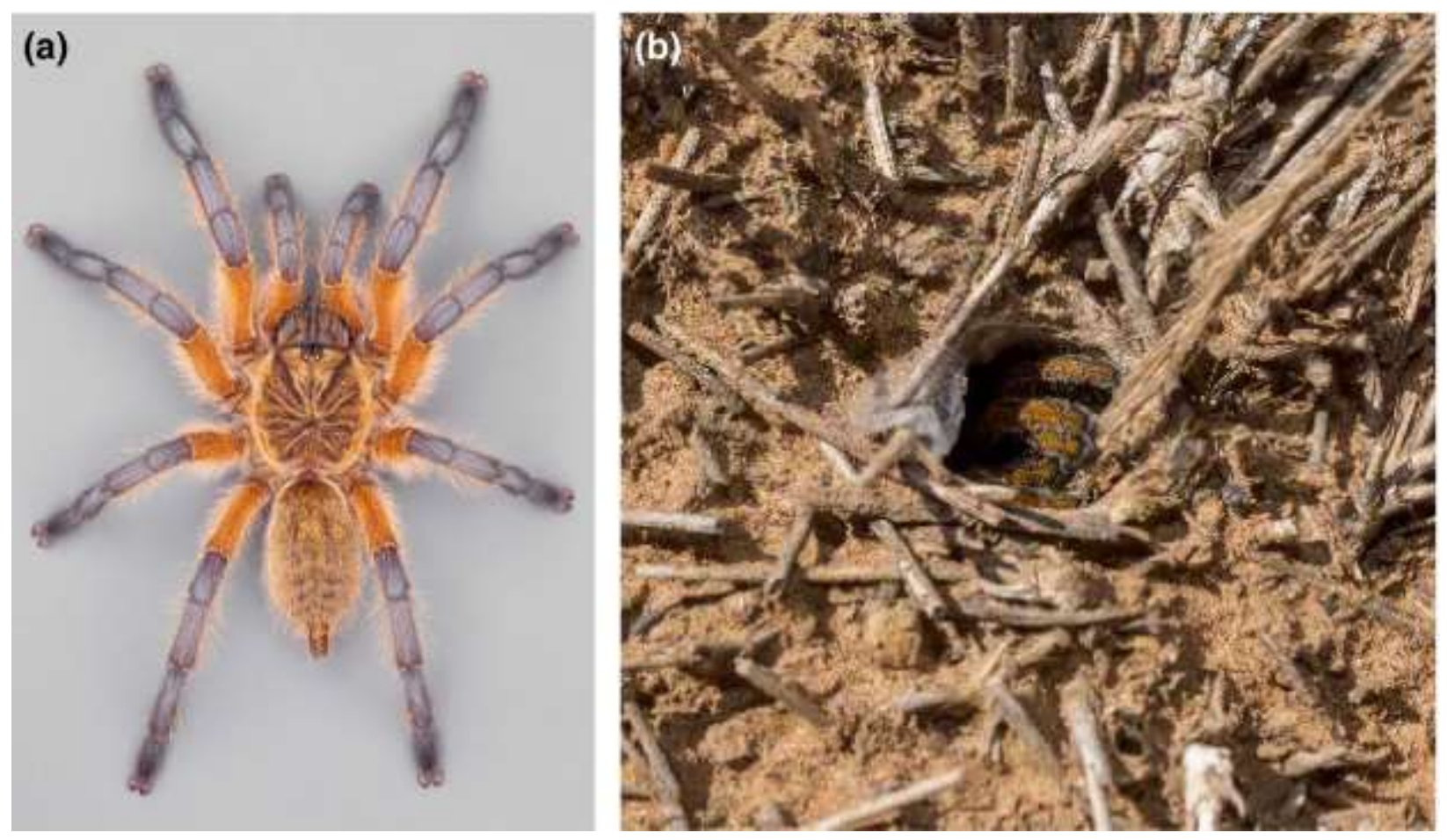

Figure 1. Examples of images from the Baboon Spider Atlas include (a) a standardised grey-card image from the photographic reference library of the Golden Blue Leg Baboon Spider, Harpactira pulchripes, and (b) a field photo showing a Lesser Baboon Spider, Harpactirella sp., in a silk-covered burrow.

Baboon spiders are threatened by illegal harvesting for the pet trade and by habitat loss. They may be particularly sensitive to these threats as they are long-lived and have low reproductive rates, with some species occupying restricted geographic ranges or having specific habitat requirements (Gallon \& Engelbrecht, 2011). Most species are brown or grey, but some have spectacular markings or coloration (Fig. 1a) that mean they are in high demand in the exotic pet trade (De Wet \& Schoonbee, 1991). Several species are bred in captivity to supply the pet trade, yet there is still demand for a supply of wild caught specimens. For this reason baboon spiders are protected in parts of South Africa by legislation against the unregulated removal of 
baboon spiders from the wild. Permits are required to collect, keep, breed and trade them (De Wet \& Schoonbee, 1991; Department of Environmental Affairs, 2015), but illegal trade still occurs with several South African species recently appearing in the international trade (Engelbrecht, pers. obs.). Despite these conservation concerns, baboon spiders are rarely studied and are therefore poorly represented in the existing South African National Survey of Arachnida database (Dippenaar-Schoeman et al., 2015).

The Baboon Spider Atlas (BSA) was initiated as a collaborative project in 2013 between scientists from the University of Pretoria and the University of Cape Town. The aim of the BSA is to document the diversity and distributions of baboon spiders in southern Africa using a combination of traditional field and collections-based approaches combined with citizen science driven data collection. In addition to compiling an occurrence database the BSA is assembling a comprehensive specimen, literature and photographic reference collection. Research using these resources will contribute to, conservation assessments and monitoring, establishing a stable taxonomy and, developing a better understanding of baboon spider biology. Here we outline our data collection methods, describe the database content and highlight preliminary results that reveal novel insights into these enigmatic spiders.

\section{Data collection for the Baboon Spider Atlas Citizen science and outreach}

Most citizen science biodiversity projects focus on charismatic taxa, like birds and butterflies (Ries \& Oberhauser, 2015; Sullivan et al., 2014). Spiders and other arachnids have a significant 'fear factor' associated with them, meaning they sometimes receive more attention than their less scary invertebrate counterparts. Baboon spiders may not be encountered frequently by citizen scientists as they live in burrows (Dippenaar-Schoeman, 2002). However, on the rare occasion when they are seen they provoke a strong response because they are large, hairy and 
considered frightening. Often a person's first response is to photograph the spider and upload the image to social media to find out if it's dangerous. We have been able to use this event chain (fear to photograph to social media post) to collect photographic occurrence records from the public.

There are two websites where citizen scientists can submit photographs of baboon spiders, the Virtual Museum website (VM, 2017) and the BSA website (BSA, 2017). Most well-resolved photographs are identifiable to species-level and after submission to the database identifications are completed by experienced taxonomic experts. In addition to the websites another valuable way to gather records are special interest Facebook groups, which have proved to be a critical resource for data collection and public engagement. These groups are monitored by BSA volunteers who encourage people to upload records themselves to the website or obtain permission to add the data (photograph, locality information etc.) to the BSA database. In the future, an expanded social media strategy will see the BSA use additional platforms (e.g. Twitter and Instagram) and include the development of a mobile phone app, all of which will increase data collection by citizen scientists. A key part of this strategy is the use of high quality photographs and video footage to generate interest in the BSA from the public, with interesting spider footage often going viral through social media. For example, Tarantupedia, a sister project to the BSA (Tarantupedia, 2017), has a YouTube channel that includes videos of spider behaviour and research field trips conducted for the BSA. The channel has 13,000 subscribers, over 6.6 million total views and the most viewed video has been watched 3.3 million times (YouTube, 2017). Translating this level of interest into public participation in submitting photographic records is a priority for expanding the citizen science component of the project.

One concern with citizen science projects is that information flows from the public to scientists yet these projects are not used by researchers to engage a wider audience in science (Bonney 
et al., 2009; Dickinson et al., 2010). An extremely important aspect of the BSA is dispelling myths about baboon spiders and addressing social media posts on the perceived danger of spiders. Incidentally, there are no documented fatalities from theraphosid bites, which usually only cause mild, localized symptoms (Herzig \& King, 2013). Additional outreach work includes giving talks, radio interviews, and publishing newspaper articles and blog posts. Although this reaches a smaller audience, the attendees of these events tend to be significantly more active, with $25 \%$ of records contributed by registered VM website users originating from six individuals.

\section{Traditional data collection approaches}

Traditional methods of collecting data on baboon spiders include data retrieval from the published literature, visiting museum collections and field sampling. Occurrence records have been extracted from the global literature for theraphosid spiders, which is available through the Tarantupedia website (Tarantupedia, 2017). Several museums in South Africa have large collections of baboon spiders, although many specimens are unidentified, misidentified, or have identifications based on outdated taxonomy. Visits to five of the major museum collections in South Africa are underway and will confirm and update identifications, and accurately georeference specimens (Chapman \& Wieczorek, 2006), resulting in approximately 2500 additional records.

Baboon spiders are difficult to survey as they occur at low abundances and exhibit cryptic behaviour such as construction of camouflaged trapdoors on their burrows (Fig. 1b). Fieldwork targets less well sampled areas and species. It also enables recording of ecological and behavioural data, specimen collection for taxonomic research and image capture for the photographic library. There are no standardised methods for field surveys of baboon spiders (Dippenaar-Schoeman, 2002), but the BSA uses three approaches; visual searching to look for signs of burrows, pitfall trapping and road cruising. Visual searching is the most successful 
method for locating baboon spiders that make open burrows or construct their retreats under surface cover, but it can miss species that construct camouflaged burrows (Fig. 1b). Pitfall trapping collects wandering spiders (Uetz \& Unzicker, 1975) but hundreds of traps are needed to sample one area and despite this intensive trapping effort the number of specimens collected still tends to be low. Road cruising is a method adopted from herpetology (Dodd et al., 1989) where roads are driven at night at a low speed to visually search for spiders wandering on the road surface. This method can be highly productive, although success tends to be erratic and appears to be strongly influenced by environmental conditions, locality, and the time of year (Engelbrecht, pers. obs).

Citizen science records are combined with records from the published literature, museum specimen data and fieldwork data into a single online database housed at the Virtual Museum (VM, 2017). This database is publicly accessible through the VM website but locations are only provided at $15 \times 15$ minute resolution because of conservation concerns related to illegal harvesting for the pet trade. For researchers, exact locality data is available and can be accessed by a variety of software programs such as GIS and R.

\section{Content and coverage of the Baboon Spider Atlas database}

The BSA is the largest existing database for baboon spider distribution with 2126 occurrence records in the database (retrieved at $5^{\text {th }}$ October 2017). Citizen science allows the BSA to gain a wide geographic coverage (Fig. 2) for a large number of records (Fig. 3) at a low cost. In July 2016 the number of citizen science records surpassed those from traditional sources and is continuing to increase rapidly (traditional, $n=887$; citizen science, $n=1239$; Fig. 3 ). Currently, the photographic reference library (see example image Fig. 1a) contains $30 \%$ of the described species in southern Africa, as well as images for several geographic varieties and undescribed 
species. The use of citizen science observations can create biased datasets therefore, we outline here the taxonomic, geographic and life stage/sex coverage of the BSA database.

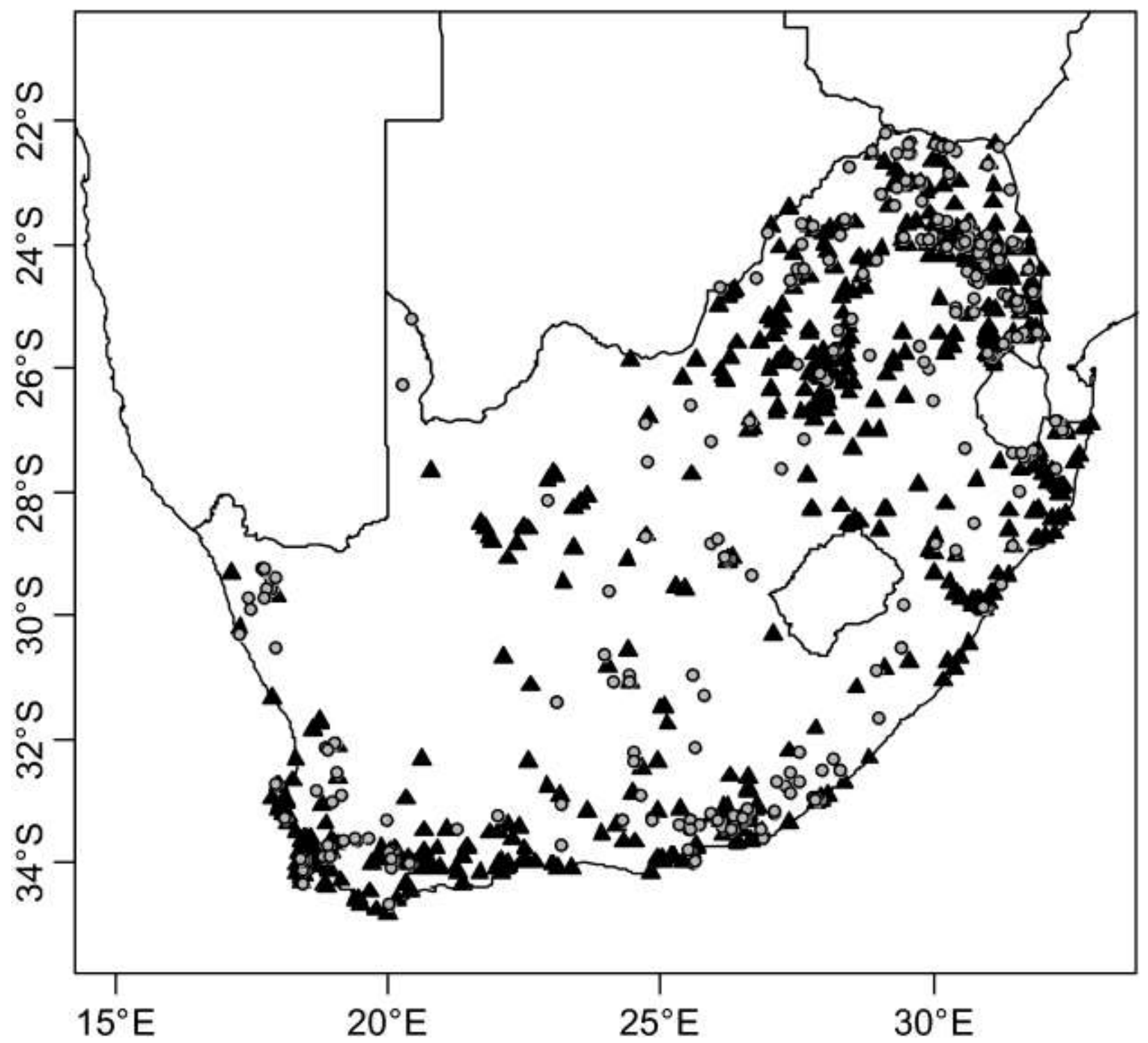

Figure 2. Map of Baboon Spider Atlas database records for South Africa using all georeferenced point localities based on traditional sources of data (grey circles, $n=438$ ) and citizen science observations (black triangles, $n=969$ ). 


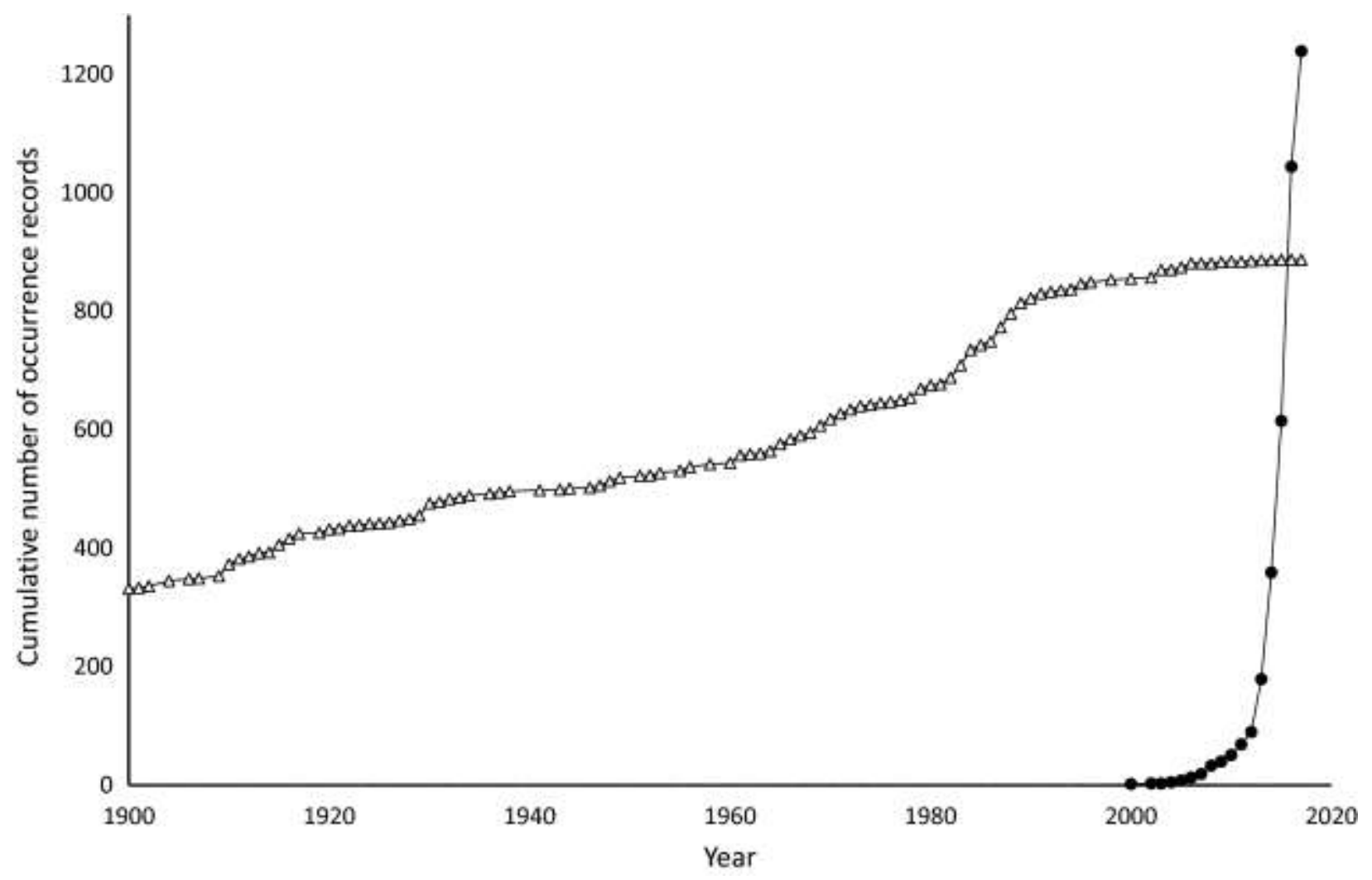

Figure 3. Cumulative number of records contributed through citizen science (black circles, $n=1239$ ), as well as traditional avenues of data collection including museum specimens and records from the published literature (white triangles, $n=887$ ). For museum and literature records, many dates are before 1900 , or are unknown, and are included here as pre-1900 records.

In the entire database less than $4 \%$ of records remain unidentified (78 unidentified vs 2048 identified). All published literature and museum records contain species-level identifications $(\mathrm{n}=$ 887), whereas $71 \%$ of citizen science records have species-level identifications (species-level, $n$ = 888; genus-level, $n=273$ ). A genus-level identification may be assigned due to taxonomic uncertainty or in cases where photographs do not show the morphology sufficiently well to facilitate an identification. Some images are of burrows only (with no spider visible) or of spiders inside their burrows, which makes identification difficult (Fig. 1b). 
All 56 described species of baboon spider in southern and eastern Africa are represented in the database, while citizen science records capture $60 \%$ of described species $(n=34)$. Two baboon spider genera have not been recorded by citizen scientists and while species from these genera are not necessarily thought to be rare, their known distributions fall in poorly sampled areas or they are easily misidentified species. Harpactira species comprise $42 \%$ of all the photographic records submitted by citizen scientists (Fig. 4) suggesting that they are more common, conspicuous or better able to survive in human-dominated areas than other species.

Augacephalus are commonly encountered when sampling burrows during fieldwork, yet comprise less than $5 \%$ of citizen science records (Fig. 4), which suggest a truly sedentary nature.

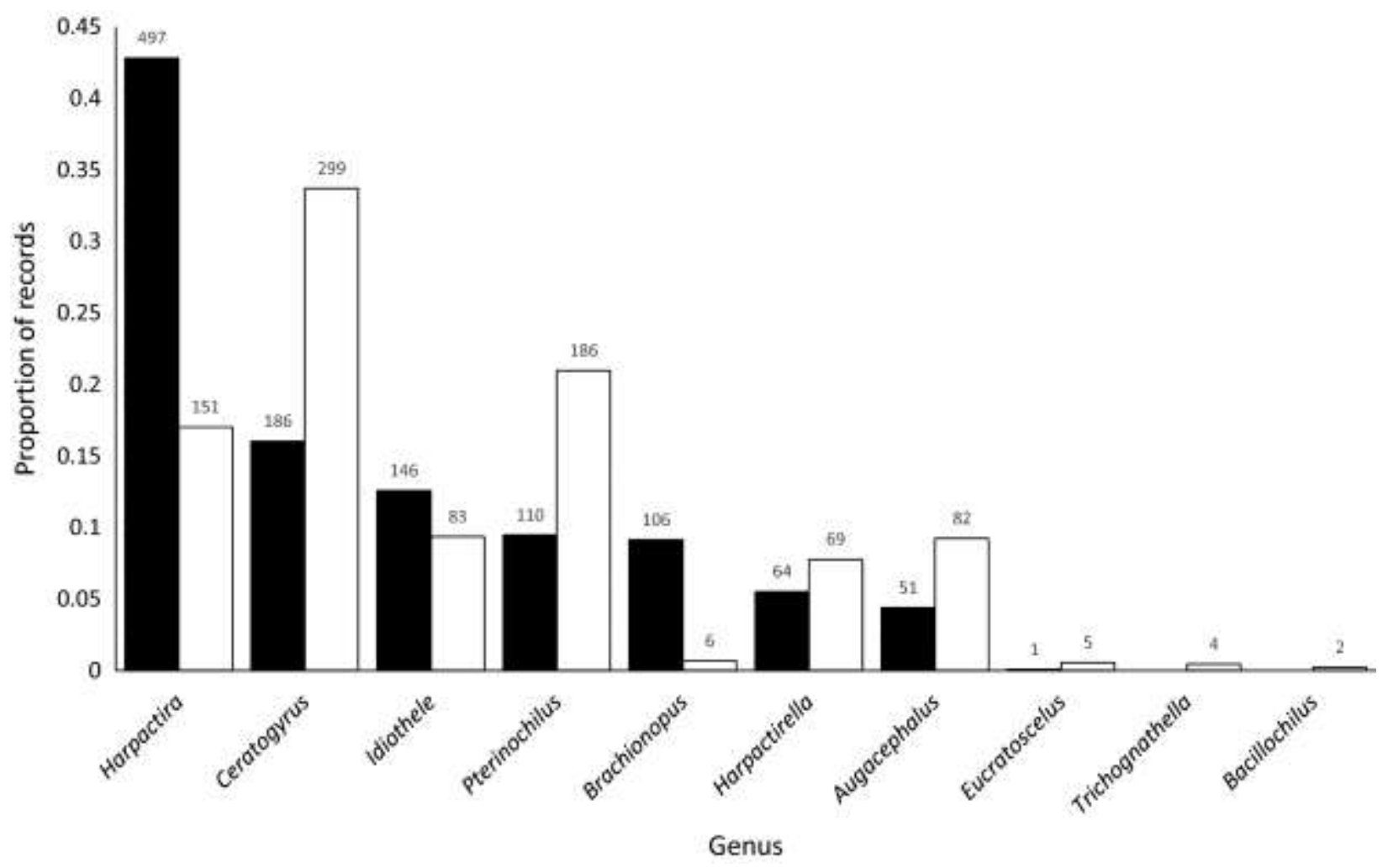

Figure 4. Proportion of records for baboon spider genera as recorded by citizen science (black, $n=1161$ ) and in traditional data sources (white, $n=887$ ). Numbers above bars equal sample size. 
The BSA database contains records from 22 African countries with the most records from South Africa $(n=1407)$, Zimbabwe $(n=210)$, and Namibia $(n=118)$. Citizen science records are mainly from South Africa (78\%, 969 of 1239 records), but there are growing numbers of records from other African countries with the top contributors being Namibia (6.2\%), Malawi (5.8\%), Zambia (2.9\%) and Mozambique (1.9\%). Within South Africa citizen science records are concentrated in the more densely populated eastern and southern regions of the country (Fig. 2). The most records are from Limpopo $(22 \%, n=216)$, the Western Cape $(21 \%, n=200)$ and KwaZulu-Natal $(15 \%, n=147)$, with the other six provinces contributing the remaining $42 \%$ of records (Mpumalanga, $n=124$; Eastern Cape, $n=81$; Northern Cape, $n=58$; Gauteng, $n=58$; North West, $\mathrm{n}=52$ Free State, $\mathrm{n}=33$ ).

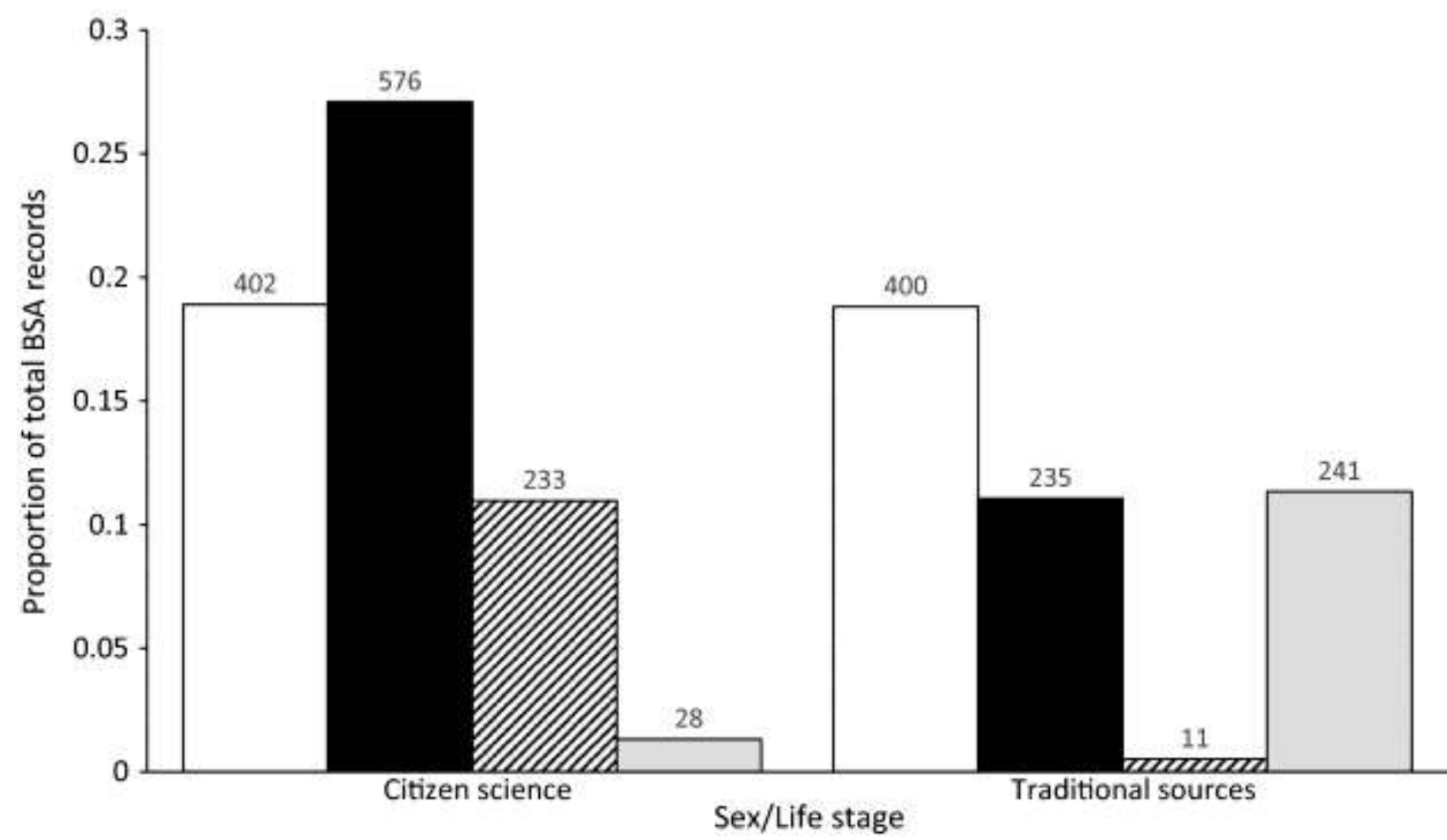

Figure 5. Sex and life stage of baboon spiders for all occurrence records in the Baboon Spider Atlas (BSA) database collected from traditional sources (museum collections and published literature, $n=887$ ) and through citizen science observations ( $n=1239$ ) for adult females (white, $n=802$ ), adult males (black, $n=811$ ), immatures (striped, $n=244$ ), and for records with no sex or life stage identification (grey, $n=269$ ). Numbers above bars equals sample size. 
Most database records are for adult spiders (approximately 76\%, Fig. 5) with similar numbers of males and females (801 female vs 810 male). Almost very few records exist in the published literature of immature spiders, which cannot be accurately identified to sex, they are frequently recorded by citizen scientists (95\% of records for immatures are from citizen scientist observations). Records without a sex or life stage assigned are mainly due to gaps in the published literature.

\section{Applications of the BSA database: preliminary analyses and results}

The data generated from biological recording schemes can be used to answer many research questions in biogeography, responses to invasive species and climate change, conservation assessment and planning, and phenology (Bishop et al., 2013; Powney \& Isaac, 2015; Robertson et al., 2010). Despite the early stage of the BSA we have already discovered surprising results, including an estimated 30 potential new species. We provide examples here that illustrate applications of the database and demonstrate some of the interesting findings that these data have revealed.

\section{Expansion of known species distributions}

The BSA dataset is most robust for South Africa, but some distribution data are available for other parts of sub-Saharan Africa. The distributions of many species are poorly known with several cases where new citizen science records have resulted in significant range extensions for a species. For example, Idiothele mira was known from the Ndumo region bordering Mozambique, but was recently photographed outside it's known range. Due to the limited distribution of $I$. mira there were concerns about the impact of illegal harvesting for the pet trade on this species. This new record shows that $I$. mira may be more widespread and possibly at lower risk of overexploitation than previously thought. In 2013 Ceratogyrus sanderi was recorded for the first time in Botswana. It was assumed to have a disjunct distribution in 
northern Namibia and Zimbabwe with no intermediate locality records (Fitzpatrick, 1994) but the 2013 record indicates a continuous distribution throughout the region.

\section{Explaining baboon spider distributions}

To our knowledge the factors that influence baboon spider distributions are unstudied, either in a global context or more specifically in Africa. Environmental variables are broadly thought to predict the distribution of biodiversity (Gaston, 2000) and based on our field observations we hypothesised that baboon spider distributions in South Africa would be most strongly predicted by precipitation variables. To test this we modelled the species distributions of the three most frequently recorded species of Harpactira, the common baboon spiders, using boosted regression tree (BRT) analyses (Elith et al., 2008) and 8 environmental predictor variables (Hijmans et al., 2005) using the gbm package (Ridgeway, 2006; see Table 1 for further methodology) in R version 3.4.1 (R Core Development Team, 2017).

We found that Harpactira atra occurs in coastal regions of the Western Cape, whereas $H$. gigas and $H$. hamiltoni occupy the eastern region of South Africa (Fig. 6). Harpactira hamiltoni and $H$. gigas occur in areas typically exhibiting more extreme rainfall patterns, with much higher rainfall in the wettest month and lower rainfall in the driest month (Table 1). These two species occupy a summer rainfall region (i.e. high summer and low winter rainfall) while the reverse is true for $H$. atra which occupies a winter rainfall region. Temperature variables confirm this pattern, with $H$. hamiltoni and $H$. gigas distributions in areas of higher mean temperatures in the wettest quarter (summer rainfall region) and $H$. atra the driest quarter (winter rainfall region). All three species distribution ranges had approximately the same maximum temperature in the warmest month, yet relative to the other species, $H$. hamiltoni occurred in areas with a much lower minimum temperature in the coldest month. 
Table 1. Summary of the relative contributions (\%), mean and range of environmental predictor variables for precipitation ( $\mathrm{mm}$ ) and temperature

$\left({ }^{\circ} \mathrm{C}\right)$ based on boosted regression tree models developed with cross validation for three species of Harpactira.

\begin{tabular}{lcccccc}
\hline Variable & \multicolumn{3}{c}{ Relative contribution } & & \multicolumn{2}{c}{ Mean (range) } \\
& H. hamiltoni & H. gigas & H. atra & H. hamiltoni & H. gigas & H. atra \\
\hline $\begin{array}{l}\text { Precipitation } \\
\text { Wettest month }\end{array}$ & 20.0 & 20.5 & 15.8 & $120.9(74-175)$ & $136.1(78-229)$ & $85.0(37-154)$ \\
Coldest quarter & 18.5 & 14.8 & 4.2 & $33.0(9-107)$ & $50.4(7-182)$ & $237.9(98-431)$ \\
Warmest quarter & 12.5 & 11.1 & 6.8 & $327.6(199-512)$ & $347.7(217-640)$ & $47.5(15-101)$ \\
$\begin{array}{l}\text { Driest month } \\
\text { Temperature }\end{array}$ & 3.2 & 5.5 & 2.5 & $9.0(2-31)$ & $14.5(1-58)$ & $13.2(2-32)$ \\
Min of coldest month & 16.2 & 11.6 & 31.0 & $1.4(-3-12)$ & $7.9(-1-15)$ & $2.9(3-10)$ \\
Max of warmest month & 14.0 & 7.7 & 11.4 & $27.5(22-33)$ & $29.2(22-34)$ & $27.6(23-32)$ \\
Mean of wettest quarter & 9.7 & 21.8 & 14.1 & $20.5(16-26)$ & $23.4(16-27)$ & $13.0(9-15)$ \\
Mean of driest quarter & 5.9 & 7.0 & 14.1 & $10.7(6-17)$ & $15.9(9-20)$ & $20.8(17-23)$ \\
\hline
\end{tabular}

Models were fitted for each species based on the presence/absence dataset and incorporating 8 environmental predictor variables. For each species, presence/absence datasets were assembled as follows. To compensate for uneven distribution of sampling effort one occurrence record per grid cell ( 0.05 degrees of latitude $x 0.05$ degrees of longitude) was randomly selected for inclusion in the presence data for each species. Pseudo-absence data was then generated for 1000 localities by defining circular regions with a $50 \mathrm{~km}$ radius around presence records and then drawing random points from within these regions. The environmental predictor variables were selected as a subset of the 19 Bioclim variables derived from the WorldClim database (version 1.4) of temperature and rainfall measurements and downloaded at a 10-minute resolution (Hijmans et al., 2005). Models were optimised following procedures described by Elith et al (2008) but in no cases were predictor variables dropped from the final models. Final model parameters were as follows; $H$. hamiltoni, data from 1046 sites, tree complexity of 5 and learning rate of $0.001 ; \mathrm{H}$. gigas, data from 1042 sites, tree complexity of 5 and learning rate of 0.0005 ; and $\mathrm{H}$. atra, data from 1049 sites, tree complexity of 5 and learning rate of 0.002 . 

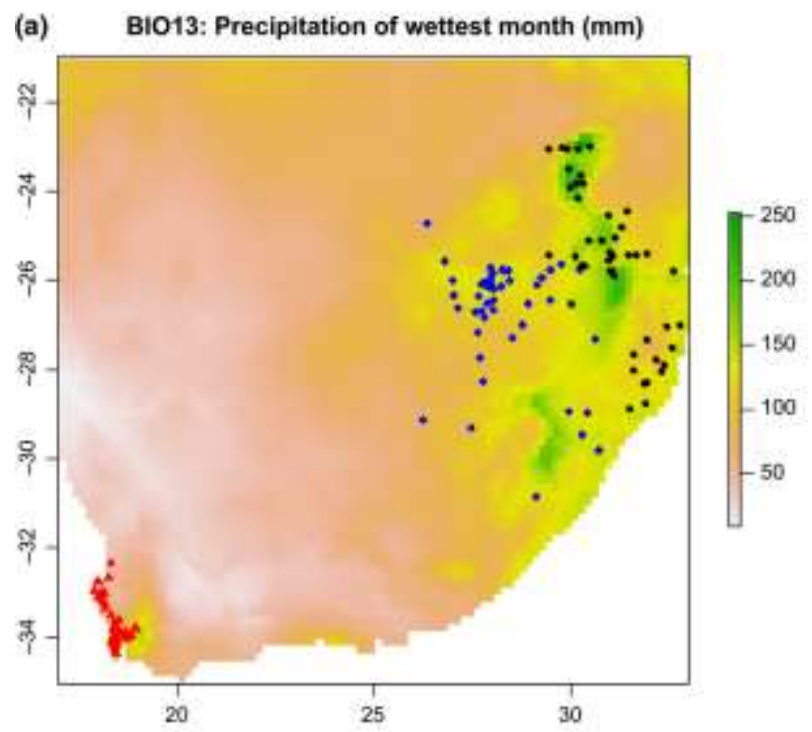

(b) BIO6: Minimum temperature of coldest month $\left({ }^{\circ} \mathrm{C} \times 10\right)$

(c)

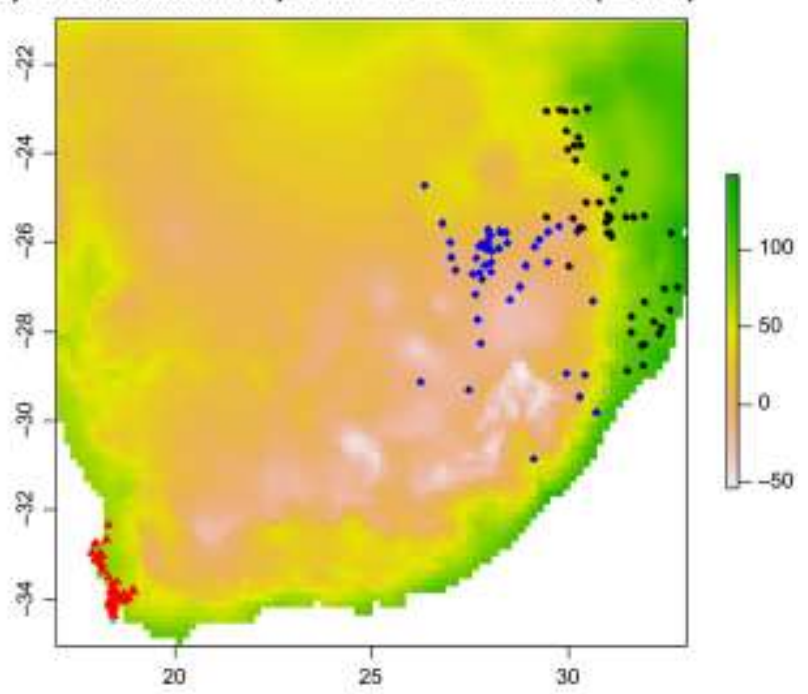

BIO8: Mean temperature of wettest quarter (" $\mathrm{C} \times 10)$

(d)
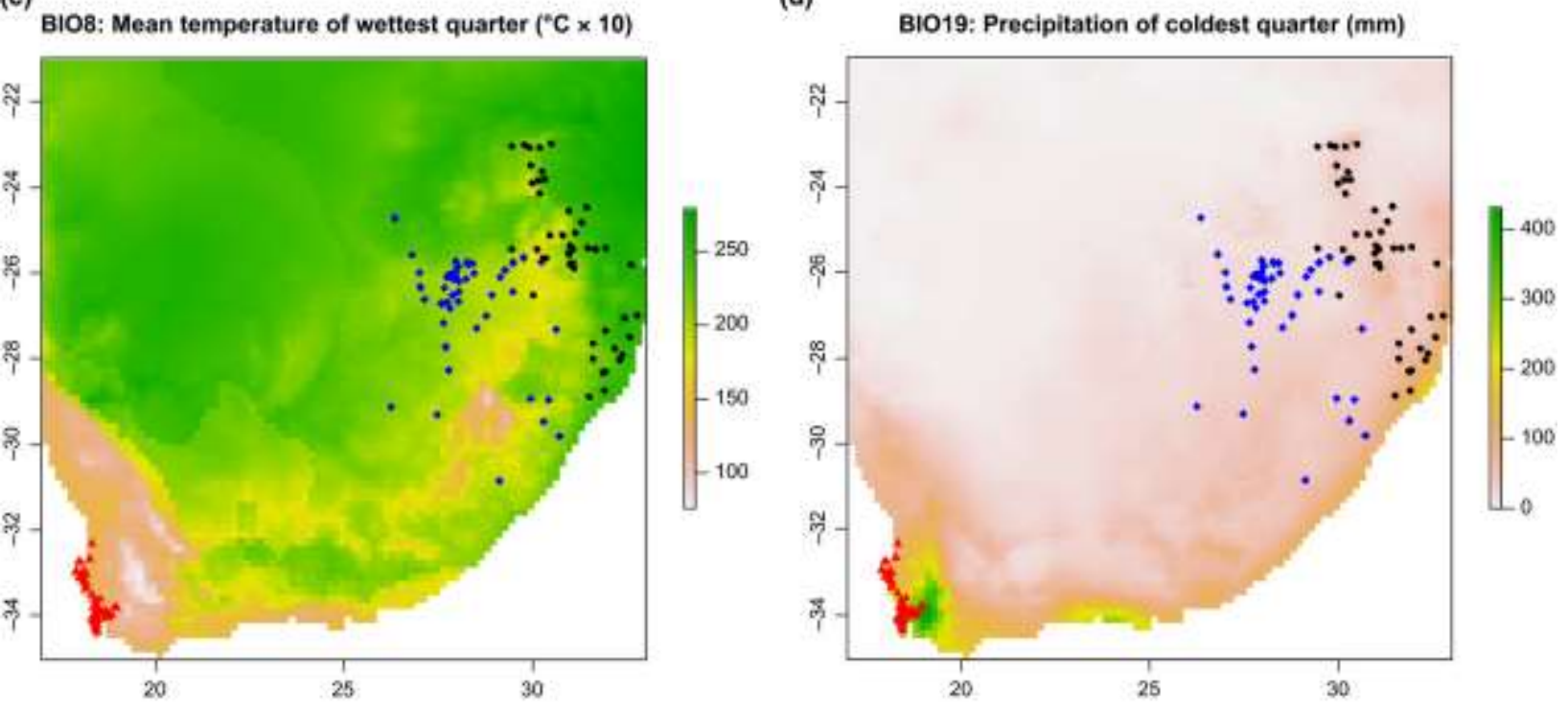

Figure 6. Climate maps for South Africa based on WorldClim data with the distribution of three baboon spider species in the genus Harpactira. Maps show the (a) precipitation of the wettest month, (b) minimum temperature of the coldest month, (c) mean temperature of the wettest quarter, and (d) precipitation in the coldest quarter. Occurrence records are shown for Harpactira atra (red triangles, $n=62$ ), Harpactira gigas (black circles, $n=55$ ), and Harpactira hamiltoni (blue diamonds, $n=49$ ).

For all three Harpactira species one of the most influential environmental variables predicting distribution patterns was the precipitation of the wettest month (Fig. 6a, Table 1). The other 
influential variables differed for each species (Table 1); for $H$. atra it was the minimum temperature of the coldest month (Fig. 6b); for H. gigas it was mean temperature of the wettest quarter (Fig. 6c); and, for H. hamiltoni precipitation in the coldest quarter (Fig. 6d). Strikingly, distribution patterns of baboon spiders seem to be most strongly predicted by how cold and wet the climate is, suggesting these conditions may be more limiting than tolerance of the hot and dry environmental conditions with which baboon spiders are usually associated.

\section{Understanding wandering behaviour}

Baboon spiders are sit and wait predators, and were thought to always stay inside or near their burrows, with the exception of adult male spiders that will wander in search of a mate (Dippenaar-Schoeman, 2002). Most BSA citizen science photographs are of wandering spiders i.e. not photographs taken of spiders in or near their burrows, and we might therefore expect that records would overwhelmingly consist of adult males. Astonishingly we found that for all citizen science records, 32\% were for adult females and 19\% of immatures (Fig. 5). The high frequency of records that were not for adult males is in complete contrast with the accepted rhetoric that baboon spiders rarely leave their burrows (Dippenaar-Schoeman, 2002). In addition to revealing a new aspect of baboon spider behaviour, this new finding may have conservation implications. Immature spiders are not thought to be able to re-establish new burrows if theirs are destroyed. For example, if, due to their small size, they are released after excavation during pet trade collections (De Wet \& Schoonbee, 1991). Given that one fifth of records show wandering by immature spiders they may naturally relocate from existing burrows, meaning that excavation would not result in mortality and pose as serious a threat to baboon spiders as previously thought. Further investigation is required to establish the purpose of this previously undocumented behaviour in adult females and immatures. 


\section{Discussion}

Baboon spider diversity appears to be grossly underestimated in southern Africa, which is surprising considering the size and conspicuous appearance of these animals. The apparent underestimation of baboon spider diversity can be attributed to a range of factors including; a lack of taxonomic attention since the original species were described; a poor representation of specimens in museum collections; and, the low density of individuals that lead to difficulties with systematic field sampling methods. Globally, the use of molecular approaches for species delimitation in theraphosid taxa have been implemented with great success (Hamilton et al., 2014) and applying these methods will be vital to resolving taxonomic uncertainty in the more problematic genera of southern African baboon spiders.

Establishing accurate distribution data for baboon spiders in southern Africa is an urgent priority for conservation planning. In South Africa, there are large data gaps in the arid central and north-western regions (Fig. 2) that need to be sampled. While we found preliminary evidence that precipitation and temperature variables might predict distributions, further research based on more comprehensive range data is required before any definitive conclusions can be drawn. Modelling baboon spider distributions could be used to determine areas where a species may be found, as well as predicting species or community-level responses to future scenarios such as climate change, habitat loss or introduction of invasive species.

It is apparent that previously held assumptions regarding basic aspects of baboon spider biology are inaccurate. Understanding the behaviour of baboon spiders is as essential in assessing their risk from anthropogenic threats as establishing their diversity and distribution patterns. Ecological studies are vital to elucidate the role of baboon spiders in ecosystems and the nature of their interactions with other organisms. 
By using citizen science, the BSA has successfully gathered data far exceeding that collected in the last hundred years of research, yet with relatively little monetary and human resource inputs. The database provides significant new insights on baboon spiders and furthermore, since data collection is ongoing the database will continue to grow through time. The BSA demonstrates that because an animal isn't considered charismatic to the public it shouldn't be excluded from citizen science projects. In fact, the 'fear factor' associated with animals like spiders can be leveraged as a way of simultaneously obtaining species records and conducting outreach. The BSA shows substantial potential in this regard and may serve as a model for projects on other poorly known taxa or for novel approaches to data collection in less developed regions. The BSA is a significant resource that will facilitate further research and aid conservation efforts for baboon spiders in southern Africa.

\section{Acknowledgements}

We are indebted to the Baboon Spider Atlas team; Ethne Engelking, Dimitri Kambas, Caitlyn Nauschutz, Catherine Sole, Hendrik Steenberg, and Taki Tsonis, who generously donate their time and skills to make this project a success. Additional thanks go to the Animal Demography Unit at the University of Cape Town for their involvement with the technical aspects of the project. Many thanks to Tom Bishop and Mark Robertson for helpful comments on drafts of the manuscript. The BSA received funding for our citizen science public engagement work via an Outreach Grant from the Royal Entomological Society, and for our museum collection work via an FBIP Data Mobilization Grant from the South African National Biodiversity Institute (SANBI). HC is supported by a UP Postdoctoral Fellowship and a SANBI Fellowship. IE is supported by a UP Postdoctoral Fellowship. 


\section{References}

Bates, M.F., Branch, W.R., Bauer, A.M., Burger, M., Marais, J., Alexander, G.J., \& de Villiers, M.S. (2014) Atlas and red list of the reptiles of South Africa, Lesotho and Swaziland. South African National Biodiversity Institute, Pretoria, South Africa.

Bishop, T.R., Botham, M.S., Fox, R., Leather, S.R., Chapman, D.S., \& Oliver, T.H. (2013) The utility of distribution data in predicting phenology. Methods in Ecology and Evolution, 4, 10241032.

Bonney, R., Cooper, C.B., Dickinson, J., Kelling, S., Phillips, T., Rosenberg, K.V., \& Shirk, J. (2009) Citizen science: a developing tool for expanding science knowledge and scientific literacy. BioScience, 59, 977-984.

BSA (2017) Baboon Spider Atlas. <www.baboonspideratlas.co.za> 4th October 2017. Chapman, A.D. \& Wieczorek, J. (2006) Guide to best practices for georeferencing. Global Biodiversity Information Facility (GBIF). <http://www.gbif.org/orc/?doc id=1288> 31st January 2017.

De Wet, J.I. \& Schoonbee, H.J. (1991) The occurrence and conservation status of Ceratogyrus bechuanicus and C. brachycephalus in the Transvaal, South Africa. Koedoe, 34, 69-75.

Department of Environmental Affairs (2015) National Environmental Management: Biodiversity Act, 2004 (Act No. 10 of 2004). 256, 112-287. Government of the Republic of South Africa, Pretoria.

Dickinson, J.L., Zuckerberg, B., \& Bonter, D.N. (2010) Citizen science as an ecological research tool: challenges and benefits. Annual Review of Ecology, Evolution and Systematics, 41, 149-

72.

Dippenaar-Schoeman, A., Haddad, C., Foord, S., Lyle, R., Lotz, L., \& Marais, P. (2015) South African National Survey of Arachnida (SANSA): review of current knowledge, constraints and future needs for documenting spider diversity (Arachnida: Araneae). Transactions of the Royal Society of South Africa, 70, 245-275.

Dippenaar-Schoeman, A.S. (2002) Baboon and trapdoor spiders of Southern Africa: an identification manual. Agricultural Research Council, Pretoria.

Dodd, C.K., Enge, K.M., \& Stuart, J.N. (1989) Reptiles on highways in North-Central Alabama, USA. Journal of Herpetology, 23, 197-200.

Elith, J., Leathwick, J.R., \& Hastie, T. (2008) A working guide to boosted regression trees. Journal of Animal Ecology, 77, 802-813.

Fazey, I., Fischer, J., \& Lindenmayer, D.B. (2005) Who does all the research in conservation biology? Biodiversity \& Conservation, 14, 917-934.

Fitzpatrick, M.J. (1994) Range extension of Ceratogyrus sanderi Strand, 1906 (Araneae:

Theraphosidae). Koedoe, 37, 121-122.

Gallon, R.C. \& Engelbrecht, I. (2011) A new Pterinochilus species from South Africa (Araneae, Theraphosidae, Harpactirinae). Arachnology, 15, 121-126.

Gaston, K.J. (2000) Global patterns in biodiversity. Nature, 405, 220-227.

Hamilton, C.A., Hendrixson, B.E., Brewer, M.S., \& Bond, J.E. (2014) An evaluation of sampling effects on multiple DNA barcoding methods leads to an integrative approach for delimiting species: a case study of the North American tarantula genus Aphonopelma (Araneae, Mygalomorphae, Theraphosidae). Molecular Phylogenetics and Evolution, 71, 79-93.

Herzig, V. \& King, G.F. (2013). The neurotoxic mode of action of venoms from the spider family Theraphosidae. Spider Ecophysiology (ed. by W. Nentwig), pp. 203-215. Springer, Berlin.

Hijmans, R.J., Cameron, S.E., Parra, J.L., Jones, P.G., \& Jarvis, A. (2005) Very high resolution interpolated climate surfaces for global land areas. International Journal of Climatology, 25, 1965-1978.

Joppa, L.N., O'Connor, B., Visconti, P., Smith, C., Geldmann, J., Hoffmann, M., Watson, J.E.M., Butchart, S.H.M., Virah-Sawmy, M., Halpern, B.S., Ahmed, S.E., Balmford, A., Sutherland, W.J., 
Harfoot, M., Hilton-Taylor, C., Foden, W., Minin, E.D., Pagad, S., Genovesi, P., Hutton, J., \& Burgess, N.D. (2016) Filling in biodiversity threat gaps. Science, 352, 416-418.

Mecenero, S., Ball, J., Edge, D., Hamer, M., Henning, G., Krüger, M., L. Pringle, E., Terblanche, R., \& Williams, M. (2013) Conservation assessment of butterflies of South Africa, Lesotho and Swaziland: red list and atlas. Saftronics (Pty) Ltd., Johannesburg \& Animal Demography Unit, Cape Town.

Powney, G.D. \& Isaac, N.J. (2015) Beyond maps: a review of the applications of biological records. Biological Journal of the Linnean Society, 115, 532-542.

$\mathrm{R}$ Core Development Team. (2017) R: A language and environment for statistical computing. $\mathrm{R}$ Foundation for Statistical Computing.

Raven, R.J. (1985) The spider infraorder Mygalomorphae (Araneae): cladistics and systematics. Bulletin of the American Museum of Natural History, 182, 1-180.

Ridgeway, G. (2006) gbm: Generalized boosted regression models. $R$ package version, 1, 55. Ries, L. \& Oberhauser, K. (2015) A citizen army for science: quantifying the contributions of citizen scientists to our understanding of monarch butterfly biology. BioScience, 65, 419-430. Robertson, M., Cumming, G., \& Erasmus, B. (2010) Getting the most out of atlas data. Diversity and Distributions, 16, 363-375.

Sullivan, B.L., Aycrigg, J.L., Barry, J.H., Bonney, R.E., Bruns, N., Cooper, C.B., Damoulas, T., Dhondt, A.A., Dietterich, T., \& Farnsworth, A. (2014) The eBird enterprise: an integrated approach to development and application of citizen science. Biological Conservation, 169, 3140.

Tarantupedia (2017) Tarantupedia. <http://www.tarantupedia.com/> 11th April 2017.

Uetz, G.W. \& Unzicker, J.D. (1975) Pitfall trapping in ecological studies of wandering spiders. Journal of Arachnology, 101-111.

VM (2017) Animal Demography Unit Virtual Museum. <http://vmus.adu.org.za/> 4th October 2017.

YouTube (2017) Tarantupedia YouTube Channel.

<https://www.youtube.com/user/Tarantupedia> 4th October 2017. 